\title{
CORPORATE SOCIAL CAPITAL AND INNOVATION PERFORMANCE: A LITERATURE REVIEW
}

\author{
Yun $\mathrm{Li}^{1}$ and Tingting $\mathrm{Zhou}^{2}$ \\ ${ }^{1}$ Associate Professor, Ginling College, Nanjing Normal University, Nanjing \\ ${ }^{2}$ Postgraduate, Ginling College, Nanjing Normal University, Nanjing
}

DOI: 10.46609/IJSSER.2021.v06i03.009 URL: https://doi.org/10.46609/IJSSER.2021.v06i03.009

\begin{abstract}
In the current era of economic globalization and complex business environment, $\mathrm{R} \& \mathrm{D}$ investment is an important source of corporate value creation and competitiveness enhancement. As an important part of R\&D investment, social capital has an inseparable relationship with enterprise technological innovation. Due to the multiple connotations of social capital and the complexity of combining with the Chinese cultural background, although there has been a large amount of literature on the relationship between corporate social capital and innovation performance, scholars have different results on the relationship between them. To this end, this article reviews and sorts out the concepts of corporate social capital and innovation performance that have been studied and their mechanism of action, and prospects for future research directions.
\end{abstract}

Keywords: Corporate social capital, Innovation performance, Mechanism of action, Review and prospects.

\section{Introduction}

Under the impact of the new round of technological revolution and industrial transformation, human society is undergoing unprecedented changes. At present, it has entered the latter part of the third industrial revolution and is setting off the sixth wave of technological revolution marked by big data, intelligent manufacturing, and 5G communications. Enterprises will also face more unknown challenges. Innovation is the first driving force to guide development. To grasp innovation is to grasp development, and to seek innovation is to seek the future. Innovation can effectively enhance the competitiveness of an enterprise, and resources are a key element that affects the success of enterprise innovation. With the increasingly fierce competition, in order to obtain sufficient resources to support innovation, companies need to rely on social 


\section{International Journal of Social Science and Economic Research}

ISSN: $2455-8834$

Volume:06, Issue:03 "March 2021"

capital embedded in social networks in addition to relying on their own resources. Based on this, this article combs the relevant research on corporate social capital and innovation performance, summarizes the connotation of corporate social capital, the measurement of corporate innovation performance, and the relationship between corporate social capital and innovation performance, and provides theoretical references for the next in-depth research.

\section{The concept and dimensions of corporate social capital}

\subsection{The concept of corporate social capital}

The three major factors of production proposed in classical economics: labor, land, and capital. Later, the concept of social capital was gradually derived from the definition of capital. The first to clarify the concept of social capital is Bourdieu (1980).He believes that social capital is synonymous with all material and non-material resources. It is a potential or actual aggregate that can add value. It is also a resource that is recognized by the public and is inseparable from an institutionalized network of relationships. James Coleman (1988)also summarized social capital comprehensively in the article "Social Capital as a Condition for Human Resource Development" and believed that social capital is a social structural resource owned by individuals and an intangible resource that is difficult to quantify. Later Putnam introduced social capital from the field of sociology to the field of economics and politics. He defined it as an organizational feature that generates trust through social networks and reciprocal norms and thus has the possibility of obtaining other capital.

The research objects of Bourdieu, Coleman and Putnam are mainly individuals with social structure, while Burt (2000) turns the research objects to the enterprise level. Enterprises have become the basic unit of social capital research, and social capital research has quickly become an important issue in business research. Although scholars have major differences on what constitutes social capital, a broad consensus is being formed. That is, social capital is a valuable asset, and its value stems from its acquisition of resources through the social relationship of an actor (Granovetter, 1992).It has the prospect of explaining different levels of performance, making the research of social capital particularly urgent in the leading management field. Compared with other forms of capital, social capital is a long-lasting, interconnected interpersonal relationship. Social capital is not liquid and is not easy to be separated from the company. It is closely linked to the organization, development and strategy of the company (Nahapiet\&Ghoshal, 1998). Therefore, as long as an enterprise can influence its development and appropriately use its value, social capital is likely to prove to be the company's most durable source of advantage.

Some domestic scholars also conducted discussions on social capital based on China's unique 


\section{International Journal of Social Science and Economic Research}

ISSN: $2455-8834$

Volume:06, Issue:03 "March 2021"

cultural background and business environment, and then put forward their own understandings. Li Lulu (1995) believes that the social relationship possessed by entrepreneurs is corporate social capital. BianYanjie et al. (2000) proposed that corporate social capital is a company's ability to establish a social network in the economic field and thereby obtain scarce resources. Chen Chuanming et al. (2004) defined social capital as a network of internal and external resources that can be mobilized by entrepreneurs in the corporate group paradigm. Li Xinjian et al. (2020) also believe that social capital refers to the value of the position of actors in an organizational structure. Based on the micro-level and meso-level social capital research, it mainly focuses on the overall structural characteristics of the social network where the actors are located and the interaction between the networks and the impact of constraints on the ability to acquire social resources.

\subsection{The dimensions of corporate social capital}

Based on the definition of the concept of social capital, domestic and foreign scholars are also studying the dimensions of social capital. In the research of foreign scholars, the most widely used is the three-dimensionality of social capital proposed by Nahapiet\& Ghoshal: structural dimension, relational dimension, and cognitive dimension. In domestic research, BianYanjie and QiuHaixiong (2000) proposed a classification of social capital dimensions with Chinese characteristics: horizontal relational capital, vertical relational capital, and social-relational capital. Afterwards, Chen Jin and Li Feiyu divided the social capital dimension into connections with leading agencies, political organizations, intermediary organizations, and financial organizations in their research, which is to deepen and expand the research of BianYanjie and QiuHaixiong. Later, the scholars also divided the internal and external social capital of the enterprise and started related research. Wei Ying (2007) introduced Likert's seven-point scale in his research to explore the internal and external social capital of enterprises. Mai Sheng et al. (2020)also used Zhao Rui's (2012)research results in the measurement of social capital to construct an index evaluation system for corporate social capital with 7 indicators. In fact, the classification of social capital by domestic scholars is also based on the three-dimensional expansion and subdivision proposed by foreign scholars. There are overlapping parts, and there is no difference in essence.

Based on the definition of social capital by domestic and foreign scholars, foreign scholars pay attention to social structure resources, while domestic scholars mostly define social capital from the dimension of social relations. In terms of subject, most scholars believe that the subject of social capital is human. However, some sociologists believe that the subject of social capital should also include enterprises and other social groups and organizations. In terms of scope, some scholars believe that the scope of social capital is broad, including many social-structural 


\section{International Journal of Social Science and Economic Research}

ISSN: $2455-8834$

Volume:06, Issue:03 "March 2021"

resources, such as norms, organizations, interpersonal relationships, and so on. Other scholars believe that social capital is the product of inconsistent concepts of social relations, and leads to differences in specific orientations, research methods, and experiences in researching social capital.

\section{The Evaluation of Enterprise Innovation Performance}

The concept of innovation was first proposed by Schumpeter. Schumpeter (1912) believed that innovation is a recombination of production factors, emphasizing the supreme role of production technological innovation and production method changes in the process of economic development. Innovation performance is the value-added reflected by the use of technology after innovation to enhance the technological capabilities of the enterprise and increase the output. Afterwards, scholars also discussed the definition of innovation performance and defined innovation performance from three different perspectives: the result of innovation, the process of innovation, and the interaction between innovation and the environment. At the same time, under the concept of different perspectives, different views on the evaluation methods of innovation performance have also been put forward.

The first view is that it should be defined from the output results of enterprise technological innovation. Hagedoorn\&Cloodt (2003) narrowly defines innovation performance as the R\&D results of new products and new technologies brought to the enterprise by enterprises through R\&D activities. Its essence is the profit index of the enterprise. Whether the enterprise reaches the innovation goal can be judged by whether its profit increases as a measurement standard (Fischer, 2013). Based on the definition of innovation performance from the perspective of innovation results, Patel \& Pavitt (1994) proposed that patents should be used as a measure of enterprise technological innovation performance. Hagedoorn\&Cloodt (2003) advocates the use of three indicators of patent quantity, patent quality and new product quantity to judge the technological innovation ability of an enterprise, and R\&D investment to judge the degree of enterprise's research and development effort. Shen Hao and Li Yuan (2010) used the growth rate of patent quantity, new product quantity, $R \& D$ investment and $R \& D$ investment return rate as more detailed indicators to measure innovation performance.

The second point of view is considered from the perspective of the impact of enterprise technological innovation. In order to maintain the competitive advantage, the innovation performance is regarded as the behavior of the members of the organization to continuously grow and shift the focus of knowledge in the process of knowledge acquisition and sharing (Han Yi et al., 2007). Therefore, Chen Jin and Chen Yufen (2006) proposed to use innovation output performance and innovation process performance as measurement indicators. Jimenez and Sanz 


\section{International Journal of Social Science and Economic Research}

ISSN: $2455-8834$

Volume:06, Issue:03 "March 2021"

Valle (2011) subdivide the research into product innovation performance, process innovation performance and management innovation performance. XieHongming et al. (2014)divided innovation performance from two perspectives of product and process. They define product performance as an innovative result, displayed in the form of product results. The performance of process innovation is more reflected in the continuous improvement of the process in the process of innovation.

The last point of view is that we should not only evaluate the value-added of single innovation activity to the enterprise but should have a comprehensive evaluation of the value of innovation. That is, not only the innovation activities of the enterprise must be considered, but also the external innovation environment. Innovation performance should reflect the results of their interaction. Innovation performance is the result of an enterprise's innovation activities and the improvement of resource allocation efficiency in the process of organically combining internal production factors with the external environment (Shen Dingrong, 2012). Therefore, Sheng Ya and Yin Baoxing (2009) proposed innovation performance evaluation indicators based on stakeholders. That is to say, in the stage of enterprise innovation's conception, $\mathrm{R} \& \mathrm{D}$, and commercialization, different stakeholders (shareholders, executives, employees, creditors, consumers, suppliers, and competitors) have different rights and requirements for innovation. Zhang Zhengang (2015) believes that the analysis of enterprise technological innovation performance should include new product innovation efficiency, quantity, quality and the resulting financial performance. Scholars not only began to look at the innovation activity itself but also paid attention to the impact on the overall operation of the enterprise.

The different perspectives of scholars have caused the academic circles to have not yet reached a unified conclusion on the concept of innovation performance. In the measurement of innovation performance, from the perspective of data availability, there may be deficiencies in the acquisition of indicators such as financial performance and market performance related to new products. The relevant indicators of patents can be obtained from the website of the State Intellectual Property Office, and the official data is highly credible and easy to obtain. However, the income method of new products as a measurement standard is more comparable and normative than the number of patents. Different measurement methods have their own advantages and disadvantages.

\section{The mechanism of social capital on innovation performance}

In the existing research theories, domestic and foreign scholars have tried to study the relationship between social capital and corporate innovation performance from various dimensions. However, scholars have divergent opinions on the formation mechanism of social 


\section{International Journal of Social Science and Economic Research}

ISSN: $2455-8834$

Volume:06, Issue:03 "March 2021"

capital, its output effects, and explaining how to play its function to achieve corporate innovation performance. At present, there is no theory that can systematically and comprehensively reveal the internal mechanism of social capital and innovation performance.

Some scholars elaborated from the perspective of knowledge acquisition and technology diffusion, and proposed that social capital is beneficial to the exchange, dissemination and accumulation of knowledge. While acquiring knowledge, enterprises can also use knowledge to carry out technological innovation. Tsai and Ghoshal (1998) believe that social capital can help companies obtain technical information while gaining market access. The innovation speed and innovation efficiency of companies can be improved, and the knowledge accumulation and learning creation between organizations can be more time-sensitive. Liu Shouxian and Yu Peng (2007) in their research more clearly stated that enterprises with higher social capital act as "bridges" in the network. This makes it easier for enterprises to realize knowledge synthesis and knowledge exchange so that it is possible to obtain innovative knowledge. Li Wei, Lu Lin, etc. (2010) also believe that companies can apply the acquired market knowledge to internal operations to improve operating performance. At the same time, enterprises must achieve mutual trust, share information on the premise of achieving common goals and norms, and form alliances in the fierce market competition environment.

Some scholars use the viewpoint of transaction cost to explain. Compared with foreign developed countries, Chinese enterprises have higher transaction costs, which have a negative impact on the improvement of their competitiveness. Liu Fengwei et al. (2009)proposed that when an enterprise has more abundant social capital and a certain level of mutual trust with external stakeholders, they will be more inclined to use a low-cost business credit model or take some measures to reduce prepaid accounts and marketing costs. This understanding is consistent with Scott (2013). Scott considers that in the absence of formal institutional support, especially in a transitional economic environment where legal protection is relatively weak, corporate social capital has the economic effect of "transaction cost savings". Enterprises usually seek informal institutional support through social relations to reduce their business risks and transaction costs.

In recent years, it has been more to use absorptive capacity theory and knowledge spillover effects to study the effect of social capital on innovation performance. From the perspective of absorptive capacity theory, Wei Ying (2007) conducted an empirical analysis of corporate data and analyzed the relationship between corporate absorptive capacity, social capital, and technological innovation performance through a scale. And it is concluded that absorptive capacity as an intermediary variable promotes technological innovation. Wang Guoshun and Yang Kun (2011) further divided social capital into internal and external and found that if 


\section{International Journal of Social Science and Economic Research}

ISSN: 2455-8834

Volume:06, Issue:03 "March 2021"

companies want to obtain more accurate external scarce knowledge, they should increase communication and communication with other companies or members. And all of this must be based on the preconditions of mutual trust, reciprocity and equality, which is also conducive to enterprises to improve their absorptive capacity. Hou Guanghui and Zhang Jianguo (2013) also pointed out that the efficiency of knowledge absorption plays a synergistic role in the relationship between scarce resources and competitive advantage. Ai Zhihong (2017) also subdivided the absorptive capacity of an organization into potential and actual absorptive capacity. She believes that the potential absorptive capacity of an enterprise can be improved by building a larger network scale and density. And the company's actual absorptive capacity can be improved by optimizing the internal organization and management of the company. The stronger the company's actual absorptive capacity, the easier it is to achieve the company's innovation performance goals. In addition, RuanAijun and Chen Jin (2015), Wu Yong and Wei Zelong (2017), Zhang et al. (2017), Martini et al. (2017) and Flor et al. (2018) have all found that the absorption and integration capabilities of enterprises are an important regulatory variable that can effectively promote enterprise innovation.

Based on the research and discussion of the mechanism of action between social capital and enterprise innovation performance by many scholars at home and abroad, this paper is more inclined to explain the relationship between the two from the perspective of enterprise absorption ability. That is, the external social capital of enterprises can provide enterprises with effective heterogeneity information, knowledge, capital and other key resources needed for innovation and development. Then the explicit and implicit knowledge obtained will be absorbed and absorbed by internal learning and integration of the original knowledge and new knowledge, so as to realize the transfer of knowledge, improve organizational behavior, and effectively use innovative resources to change the mode of operation. The internal social capital of the enterprise can form the common values, trust, and so on through the construction of the enterprise culture, and it ensures the learning organization and the integration of resources in the internal social network. The ability of enterprise knowledge absorption also determines the degree of creative transformation and utilization through learning and integration mechanism. Enterprises need to identify and understand external heterogeneous knowledge, digest external valuable knowledge, and then commercialize the application of the absorbed new knowledge, and export new products and new technologies, thereby affecting the innovation performance of the enterprise. 


\section{International Journal of Social Science and Economic Research}

ISSN: $2455-8834$

Volume:06, Issue:03 "March 2021"

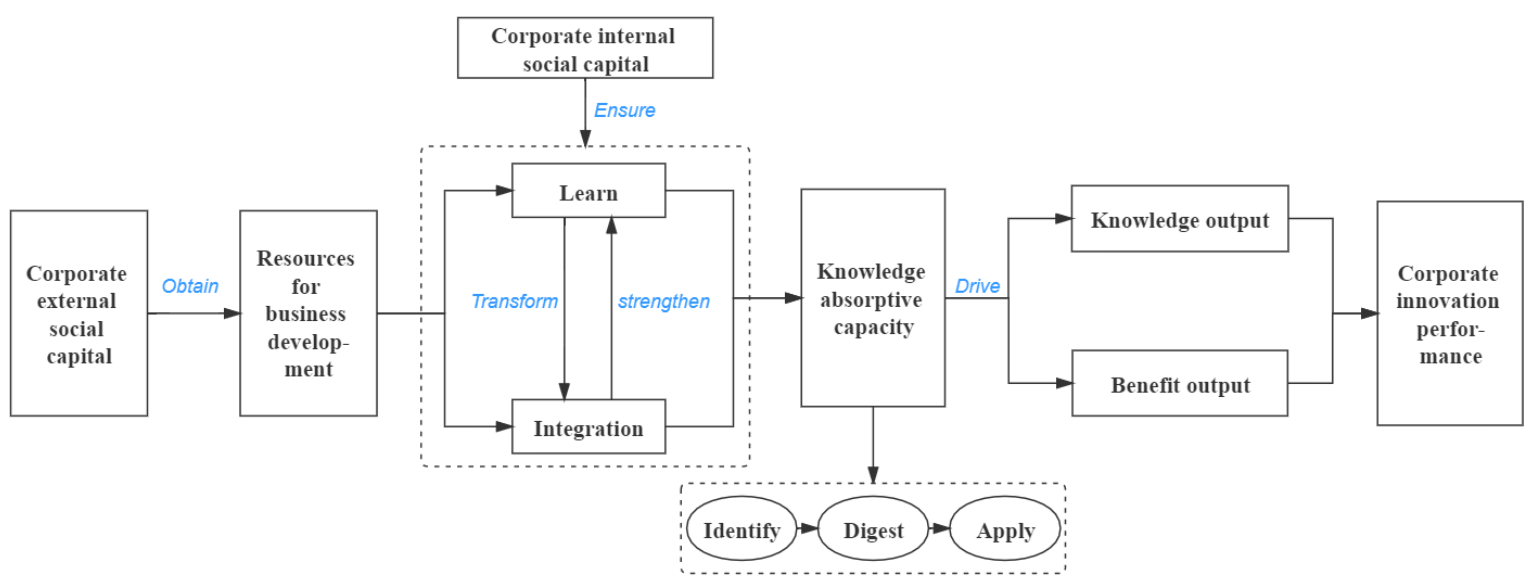

Fig. 1.The framework diagram of the mechanism of corporate social capital and innovation performance

On the mechanism of interaction between social capital and corporate innovation performance, many scholars have similar views: social capital is an important resource for enterprises, and social capital has a positive effect on corporate innovation performance. Most research results show that social capital plays a role in promoting the generation of new ideas and the diffusion of new technologies. However, most of the existing studies only consider the positive effects, while ignoring the negative effects. Sheng et al. found in 2011 that the effect of social capital on enterprise development is also different by the stage of enterprise development and the specific environment in which the enterprise is located. Social capital does not always play a role in promoting. Social capital still needs to be combined with the environment to judge whether the relationship between social capital and enterprise innovation is promotion, independence or conflict. In China's business environment, Wan Jianxiang and Zhong Yiting (2018) also found that under the subdivision of the dimensions of social capital, government-enterprise relationship capital plays different roles in different industries. It has shown restraint on traditional industries and promoted high-tech industries. Therefore, the mechanism of interaction between social capital and enterprise innovation performance should also be analyzed in conjunction with specific industry characteristics, so as to correctly recognize the functional boundaries of corporate social capital under the heterogeneity of the innovation enterprise subject.

\section{Conclusion and Prospects}

Domestic and foreign scholars have conducted extensive research on the relationship between social capital and corporate innovation performance. This article defines the concepts of social capital and innovation performance and summarizes the mechanism of action between them. 


\section{International Journal of Social Science and Economic Research}

ISSN: $2455-8834$

Volume:06, Issue:03 "March 2021"

Judging from the existing literature, future research on the relationship between social capital and corporate innovation performance should pay attention to some related issues.

The measurement of variables can be improved. Regardless of whether it is for social capital or for innovation performance, there are many measurement indicators in existing research, but due to the limitation of data acquisition channels, the measurement of many indicators cannot fully and reasonably display the variables.

The internal mechanism theory of social capital and enterprise innovation performance is still not perfect and unified. Researchers combine knowledge acquisition, technology diffusion, transaction costs, absorptive capacity and knowledge spillover effects to discuss and demonstrate their mechanism. Undeniably, this provides a partial explanation for their relationship. But the black box still exists, and scholars need to continue to explore.

In addition, scholars at home and abroad are still divided on the effect of social capital on innovation performance. According to the conclusions of most researchers, corporate social capital should promote the increase of innovation performance, but in fact, there are phenomena that contradict the conclusions. In the context of the Internet+ era of cross-border integration of countries, social capital has become a key soft indicator for the evaluation of corporate comprehensive strength. Therefore, it is necessary to combine the heterogeneity of enterprises to conduct in-depth discussions on the impact of corporate social capital on innovation performance.

\section{References}

[1]. Bourdieu P.. Le capital social:Notes previous[J].Actes De La Recherche En Sciences Sociales, $1980(3): 3 \sim 6$.

[2]. Coleman J. S.. Social capital in the development of human capital:The ambiguous position of private schools[J].Catholic Schools, 1988(20):95 120 .

[3]. Burt R. S.. Structural Holes: the Social Structure of Competition[M]. Cambridge, MA: Harvard University Press, 1992.

[4]. NahapietJ..Ghoshal S.. Social capital, intellectual capital, and the organizational advantage[J]. Academy of Management Review, 1998(2):242 256.

[5]. GranovetterM..Economic. Action and Social Structure:The Problem of 
International Journal of Social Science and Economic Research

ISSN: 2455-8834

Volume:06, Issue:03 "March 2021"

Embeddedness[J]American Journal of Sociology, 1985, 91(3):481—510.

[6]. Zhou Juan. A review of theoretical research on the concept and measurement of social capital[J]. Reform and Opening, 2010(20): 80-81.

[7]. Li Lulu. Social Capital and Private Entrepreneurs: The Special Impetus for the Transformation of China's Social Structure [J]. Sociological Studies, 1995(06): 46-58.

[8]. BianYanjie, QiuHaixiong. The Social Capital of Enterprises and Its Efficiency [J]. Social Sciences in China, 2000, (2): 89-90.

[9]. Zhou Xiaohu, Chen Chuanming. Corporate Social Capital and Sustainable Competitive Advantage [J]. China Industrial Economics, 2004(05): 90-96.

[10]. Li Xinjian, Peng Yongcui, Zhu Tong. Research on Institutional Distance, Social Capital and the Legality of Chinese Enterprises' Overseas M\&As [J]. Journal of Chongqing University of Science and Technology(Social Sciences Edition), 2020(01): 43-47.

[11]. Chen Jin, Li Feiyu. Social capital: its sociological meanings to technological innovation[J]. Studies in Science of Science, 2001(03): 102-107.

[12]. Wei Ying. Corporate Social Capital and Technological Innovation: An Empirical Research Based on Perspective of Absorptive Capacity[J]. China Industrial Economics, 2007(9): 119 127.

[13]. Zhao Rui, Chen Jinlong. The Design of Enterprise Social Capital Index and Measure[J]. Science \& Technology Progress and Policy, 2012, 29(13): 93-97.

[14]. Mai Sheng, Zhang Wenrui, Zheng Jie. Corporate Social Responsibility and Corporate Social Capital: Based on the Moderating Effect of Marketization Degree and Industry Competitive Position[J]. Friends of Accounting, 2020(02): 13-19.

[15]. Hagedoorn J, Cloodt M. Measuring innovative performance: is there an advantage in using multiple indicators?[J]. Research Policy, 2003, 32(8):1365-1379.

[16]. Fischer T, Henkel J. Complements and substitutes in profiting from innovation-A choice experimental approach. Research Policy,2013, 42(2):326-339.

[17]. Shen Hao, Li Yuan. A research on the effect of alliance relationship and environmental dynamics on innovation performance[J]. Scientific Research Management, 2010, 31(01): 77-85. 
International Journal of Social Science and Economic Research

ISSN: 2455-8834

Volume:06, Issue:03 "March 2021"

[18]. Han Yi, Liao Jianqiao, Long Lirong. Model of development and empirical study on employee job performance construct [J]. Journal of Management Sciences in China, 2007(05): 62-77.

[19]. Chen Jin, Chen Yufen. The Study of Indictors System on Technological Innovation Performance in Enterprises[J]. Science of Science and Management of S.\& T., 2006(03):86-91.

[20]. XieHongming, Zhang Ying, Cheng Cong, Chen Ying. The impact of network embedding on technical innovative performance based on the perspective of learning ability[J]. Science Research Management, 2014, 35(12): 1-8.

[21]. Shen Dingrong, Wang Chen. Relationship study about Dynamic Capabilities and Technological Innovation Performance [J]. Scientific Management Research, 2012, 30 (2): 5458.

[22]. Sheng Ya, Yin Baoxing. Review on the Organization and Technology Innovation Management of Complex Products and Systems[J]. Science \& Technology Progress and Policy, 2009, 26(05): 157-160.

[23]. Zhang Zhengang, Chen Zhiming, Li Yunjian. A study on the relationship between open innovation,absorptive capacity and firm's innovation performance [J]. Science Research Management, 2015, 36 (03): 49-56.

[24]. Liu Shouxian, Yu Peng. Social Capital and Enterprise Technology Innovation[J]. Gansu Theory Research, 2007(05): 84-86.

[25]. Li Wei, Lu Lin, Chen Nina. Analysis of the impact of corporate social capital on business performance: based on the perspective of market knowledge capabilities[J]. Modern Management Science, 2010(10): 99-101.

[26]. Liu Fengwei, Li Lin, XueYunkui. Trust, Transaction Cost and Mode of Trade Credit [J]. Economic Research Journal, 2009, (8): 60-71.

[27]. Scott G..Board Composition Beyond Independence: Social Capital, Human Capital, and Demographics[J]. Journal of Management, 2013: 39(1).

[28]. Wang Guoshun, Yang Kun. An Empirical Study of the Influence of Social Capital and Absorptive Capacity on innovation performance [J]. Journal of Management Science, 2011, 24(05): 23-36. 


\section{International Journal of Social Science and Economic Research}

ISSN: $2455-8834$

Volume:06, Issue:03 "March 2021"

[29]. Hou Guanghui, Zhang Jianguo. Can Corporate Social Capital Improve Technological Innovation Performance?An Empirical Study Based on the Moderating Effect of Absorptive Capacity Variable[J]. Contemporary Finance \& Economics, 2013(02): 74-86.

[30]. Ai Zhihong. The Theoretical Evolution and the Research Prospect of Absorptive Capacity [J]. Journal of Technical Economics \& Management, 2017(01): 38-42.

[31]. RuanAijun, Chen Jin. Impact of formal/informal knowledge search breadth on innovation performance:The moderating role of network embeddedness and absorptive capacity[J]. Studies in Science of Science, 2015, 33(10): 1573-1583.

[32]. Wu Yong, Wei Zelong. Dual knowledge exploration, dynamic resource bundling and radical innovation[J]. Science Research Management, 2017, 38(12): 11-19.

[33]. Ye Jiangfeng, Chen Shan, Hao Bin. How does Knowledge Search Influence Enterprise Innovation Performance? A Literature Review and Prospects[J]. Foreign Economics \& Management, 2020, 42(03): 17-34.

[34]. Li Sihai, Gao Li. Social Capital, R\&D Investment and Enterprise Performance Based on the Perspective of Instrumental Utility Heterogeneity [J]. Science of Science and Management of S.\& T., 2014, 35(10): 105- 115.

[35].Cao,Simsek,Jansen.CEO Social Capital and Entrepreneurial Orientation of the Firm:Bondin g and Bridging Effects[J].Journal of Management, 2015，41(7):1957-1981.

[36]. Sheng S.B.,ZhouK.,LiJ.J.The Effects of Business and Political Ties on Firms Performance:Evidence from China[J].Journal of Marketing, 2011， 75(2) :1-15

[37]. Wan Jianxiang, Zhong Yiting. The Influence of Social Capital on Enterprise Performance:Based on the Economic Transition Stage of China [J]. Management Review, 2018, 30(01): 60-66.

[38]. Bonfim,Segatto,Takahashi.Social capital dimensions, innovation, and technology in Europe:a case-studies meta-synthesis[J].International Journal of Innovation:[J] Journal,2018,6(3):232-255.

[39]. Wang Y, Li J, Furman J L. Firm Performance and State Innovation Funding : Evidence from China’s Innovation Program[J]. Research Policy, 2017, 46（6） : 1142-1161. 